\title{
The Reasons for Discrepancies in Target Volume Delineation
}

\author{
A SASRO Study on Head-and-Neck and Prostate Cancers
}

\author{
Wendy Jeanneret-Sozzi', Raphaël Moeckli², Jean-François Valley², Abderrahim Zouhair', \\ Esat Mahmut Ozsahin', René-Olivier Mirimanoff' on Behalf of SASRO ${ }^{3}$
}

\begin{abstract}
Purpose: To understand the reasons for differences in the delineation of target volumes between physicians.
Material and Methods: 18 Swiss radiooncology centers were invited to delineate volumes for one prostate and one head-and-neck case. In addition, a questionnaire was sent to evaluate the differences in the volume definition (GTV [gross tumor volume], CTV [clinical target volume], PTV [planning target volume]), the various estimated margins, and the nodes at risk. Coherence between drawn and stated margins by centers was calculated. The questionnaire also included a nonspecific series of questions regarding planning methods in each institution.

Results: Fairly large differences in the drawn volumes were seen between the centers in both cases and also in the definition of volumes. Correlation between drawn and stated margins was fair in the prostate case and poor in the head-and-neck case. The questionnaire revealed important differences in the planning methods between centers.

Conclusion: These large differences could be explained by (1) a variable knowledge/interpretation of ICRU definitions, (2) variable interpretations of the potential microscopic extent, (3) difficulties in GTV identification, (4) differences in the concept, and (5) incoherence between theory (i.e., stated margins) and practice (i.e., drawn margins).
\end{abstract}

Key Words: Tumor volume delineation · Radiotherapy · Prostate cancer · Head-and-neck cancer

Strahlenther Onkol 2006;182:450-7

DOI 10.1007/s00066-006-1463-6

\section{Die Ursachen unterschiedlicher Markierung der Zielvolumina. Eine SASRO-Studie zu Prostata- und HNO-Karzinomen}

Ziel: Die Ursachen für die unterschiedliche Markierung der Zielvolumina zwischen Ärzten sollten aufgeklärt werden.

Material und Methodik: 18 schweizerische onkologische Bestrahlungszentren wurden aufgefordert, die Zielvolumina eines Prostata- und eines HNO-Karzinoms einzuzeichnen. Ein Fragebogen wurde zusätzlich beigefügt, um die Unterschiede in der Definition der Volumina (GTV [",gross tumor volume“], CTV [klinisches Zielvolumen], PTV [Planungszielvolumen]) sowie in der Bestimmung der Sicherheitssäume und der Risiko-Lymphknotenstationen abzuschätzen. Die Kohärenz zwischen gezeichneten und geplanten Sicherheitssäumen wurde berechnet. Der Fragebogen umfasste auch eine Reihe unspezifischer Fragen bezüglich Planungsmethoden in der jeweiligen Klinik.

Ergebnisse: Es wurden ziemlich große Unterschiede zwischen gezeichneten und geplanten Sicherheitssäumen festgestellt. Die Korrelation war beim Prostatakarzinom mäßig, beim HNO-Fall schwach. Der Fragebogen offenbarte erhebliche Unterschiede in den Planungsmethoden zwischen den verschiedenen Kliniken.

Schlussfolgerung: Diese großen Unterschiede ließen sich durch unterschiedliche Kenntnis/Interpretation 1. der ICRU-Definitionen und 2. der möglichen mikroskopischen Tumorausdehnung, 3. Schwierigkeiten bei der GTV-Erfassung, 4. Unterschiede bezüglich des Konzepts und 5. Inkohärenz zwischen Theorie (d.h. geplante Sicherheitssäume) und Praxis (d.h. gezeichnete Sicherheitssäume) erklären.

Schlüsselwörter: Markierung der Zielvolumina · Strahlentherapie · Prostatakarzinom · HNO-Tumoren

\footnotetext{
${ }^{1}$ Department of Radiation Oncology, University Hospital of Lausanne, Switzerland,

${ }^{2}$ University Institute of Applied Radiophysics, Lausanne, Switzerland,

${ }^{3}$ Scientific Association for Swiss Radiation Oncology, Hospital La Source, Lausanne, Switzerland.
} 


\section{Introduction}

Conformal 3-D radiotherapy aims at delivering the largest possible and the most homogeneous radiation dose to a tumor target while keeping the dose to surrounding normal tissues to a minimum. Thus, the prime step in radiotherapy planning is to define and to delineate a target volume in three dimensions in order to produce a treatment volume which will encompass the tumor with as much precision as possible.

As discussed in more detail elsewhere [18], the routine use of 3-D treatment planning in curative radiation therapy and the growing implementation of intensity-modulated radiotherapy (IMRT) [5] in many centers or yet in a few centers proton therapy [17] require a very accurate knowledge of the volumes to be treated, with a good reproducibility, not only within radiotherapy departments but also between departments. Older techniques used larger and unshaped fields, and this has led to either a limitation of the total dose with many treatment failures or to an excessive rate of complications. Conversely, new technologies, such as IMRT, if not associated with an extremely careful definition of the target, may lead to an excess of geographic misses and local failures.

The International Commission on Radiation Units and Measurements (ICRU) Reports 50 and 62, published in 1993 and 1999, have provided a formal definition to describe volumes in radiation planning [10,11]. In brief, the gross tumor volume (GTV) is the gross extent of the malignancy. The clinical target volume (CTV) is the GTV plus a margin to include local subclinical tumor spread. The CTV can also include regional nodes. The GTV and CTV are based on anatomic, biological and clinical considerations and do not account for the technical factors of treatment. The planning target volume (PTV) is the CTV plus a margin to ensure that the CTV receives the prescribed dose.

Previous studies, including some carried out in our department, have shown that large discrepancies were found when different physicians were asked to delineate volumes in the same patient $[7,13,14,20,22,26-29,31]$. However, few studies have tried to analyze and explain the discrepancies related to differences in medical understanding, knowledge and definition of volumes and to all clinical steps that contribute to the dose delivery process. These discrepancies are worrisome when considering the high precision achieved with conformal therapy and even more with IMRT. It has been stated that inadequate definition of the GTV/CTV leads to a systematic geographic miss of the tumor and that, for some locations, these inconsistencies may dominate all other errors in radiotherapy planning and delivery [31]. To help understand, at least in part, the reasons why there are wide variations in volume delineation between physicians, we undertook a study where we chose both an easy case for planning (prostate) and a more difficult one (head and neck) and compared the results obtained.

\section{Material and Methods}

18 Swiss radiation oncology centers were invited to participate in this SASRO study. Clinical and radiologic data of a prostate and a head-and-neck case were sent and local physicians were asked to delineate GTV, CTV and PTV according to ICRU 50 [10], and to complete a related questionnaire. Eleven Swiss centers agreed to participate and have completed the study. Patient description and CT imaging were sent on CD-ROM, along with an ad hoc questionnaire. The two cases were the following:

(1) a 76-year-old man with a PSA (prostate-specific antigen) 6 , Gleason 4, stage T1c N0 M0 prostatic adenocarcinoma;

(2) a 72-year-old man with a well-differentiated squamous cell carcinoma of the base of the tongue, stage T3 N0 M0.

Anonymous data analysis and interpretation were ensured. In brief, the physical part of the study was based on the analysis of the consistency of the delineated volumes in a two-step procedure. The first included examination of 2-D contour delineation in the three main planes and calculation of their extension in the three main axes. In the second step, the correlation of the volume delineation made at the different institutions was established [18].

\section{Questionnaire Specific to the Two Cases}

In this part of the questionnaire, physicians were asked how they would specifically define the GTV in each of the two situations and if they had difficulty in defining it, especially concerning its various limits in space. With regard to the CTV, besides specific definition, questions were related to the distance (margin) in millimeters between GTV and CTV physicians would use in the two cases, and if any (and which) adjacent organ(s) had to be excluded from the CTV. With regard to the PTV, physicians had to give the relevant definition and the margin estimate in all directions. For the head-and-neck case, physicians had to name the lymph nodes at risk to be encompassed in the volume irradiated. In the final analysis, we looked not only at the intercenter variations between volumes [18], but also at the intraobserver coherence between the volumes drawn and the answers given in the questionnaire (i.e., margins drawn and stated).

\section{Questionnaire with General Information not Specifically Related to the Two Cases}

Although each physician received the same material for the purpose of this study, we also wanted to know the differences in concept and in the routine planning between each individual institution. This part of the questionnaire therefore contained questions on CT planning techniques (use of contrast, interval between slices), how the GTV is generally established (use of additional diagnostic tools, possible help from other colleagues such as radiologists or surgeons), and the use of immobilization devices. 


\section{Poststudy Questionnaire}

Once all results concerning the volumes had been collected from the institutions and analyzed, anonymized transverse and sagittal delineation of prostate and head-and-neck volumes of
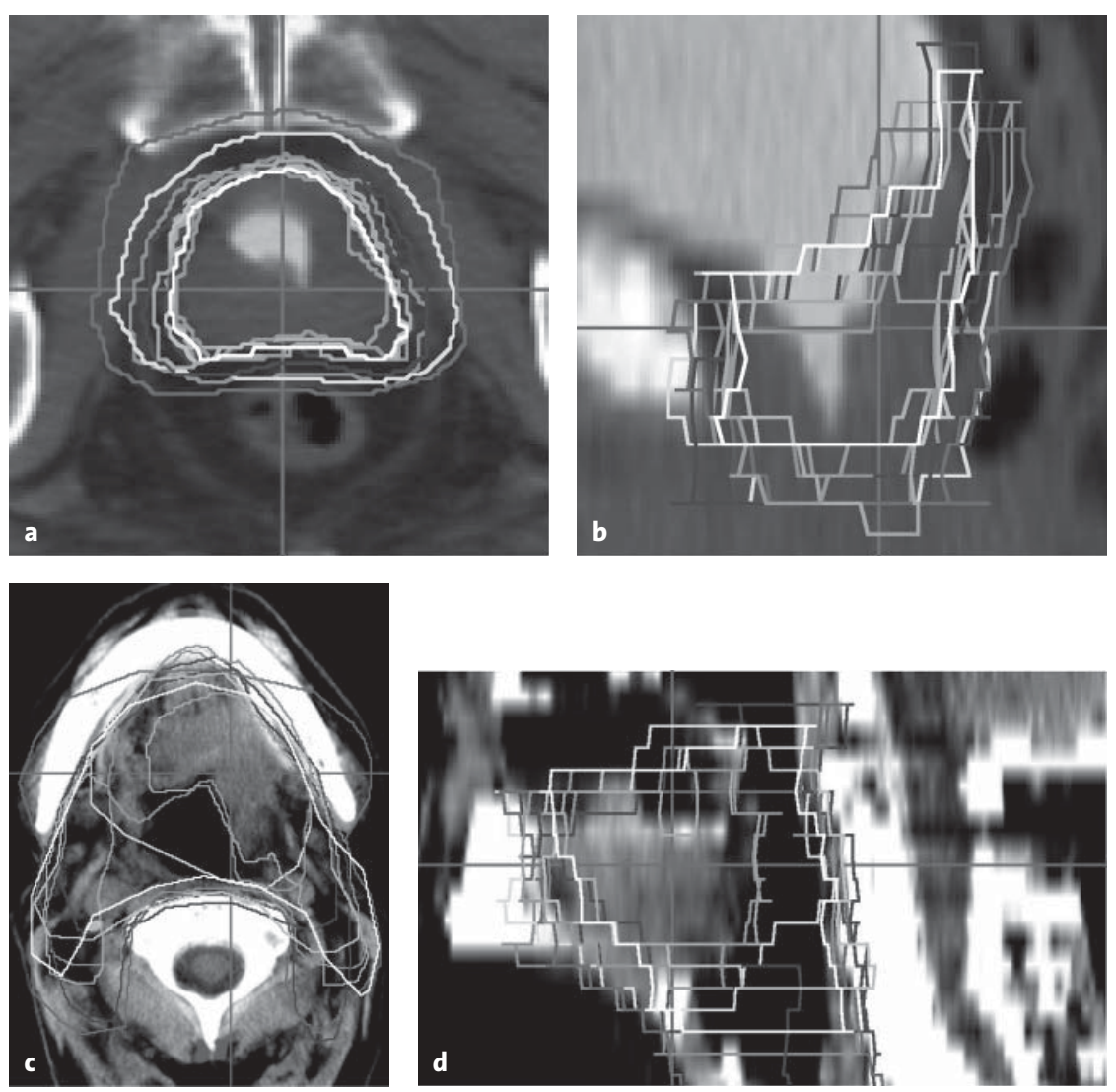

Figures 1a to 1d. Demonstration of the variations in the CTV delineation on axial and sagittal planes for the prostate $(a, b)$ and the head-and-neck case $(c, d)$.

Abbildungen 1a bis 1d. Darstellung der Abweichungen bei der Bestimmung des CTV in den frontalen und sagittalen Ebenen beim Prostata- $(a, b)$ und HNO-Karzinom $(c, d)$.
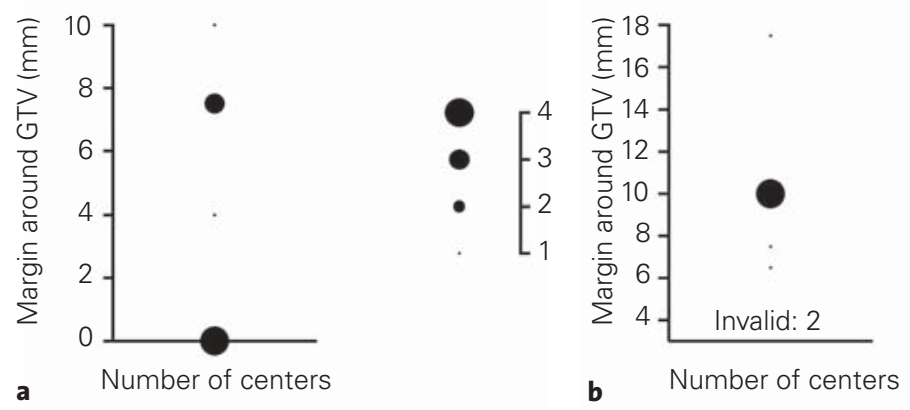

Figures $\mathbf{2 a}$ and $\mathbf{2 b}$. Distribution of reported margins around GTV for extracting the CTV for the prostate (a) and the head-and-neck case (b).

Abbildungen $\mathbf{2 a}$ und $\mathbf{2 b}$. Verteilung der um das GTV gezeichneten Sicherheitssäume bei der Bestimmung des CTV beim Prostata- (a) und HNO-Karzinom (b). all centers were sent to each physician with a new questionnaire. Physicians were asked to analyze the differences between all volumes drawn and to comment. They were asked to compare their own volume to that of other centers and to state if they still thought that their delineation was the best. They were also invited to formulate their own hypothesis as to the possible causes for these large volume discrepancies.

\section{Results}

\section{Volumes Drawn}

As expected, there were wide variations between the volumes drawn by the eleven physicians. Regarding the prostate case, the mean CTV was $105.3 \mathrm{~cm}^{3}$, with a minimum of 39.9 and a maximum of 180.5 $\mathrm{cm}^{3}$, the mean PTV was $218.2 \mathrm{~cm}^{3}$ (minimum 149.7, maximum $289.1 \mathrm{~cm}^{3}$; Figures $1 \mathrm{a}$ and $1 \mathrm{~b})$. With regard to the head-andneck case, the mean GTV was $46.4 \mathrm{~cm}^{3}$ (minimum 19.0, maximum $63.8 \mathrm{~cm}^{3}$ ), the mean CTV $327.0 \mathrm{~cm}^{3}$ (minimum 119.7, maximum $601.6 \mathrm{~cm}^{3}$ ), and the mean PTV $527.5 \mathrm{~cm}^{3}$ (minimum 364.7, maximum $654.0 \mathrm{~cm}^{3}$; Figures $1 \mathrm{c}$ and $1 \mathrm{~d}$ ).

\section{Responses to the Questionnaire Specific to the Two Cases \\ (Eleven Centers) \\ Definition of the GTV}

The answers for the GTV definition were inconsistent in both situations. In three centers, GTV was said to represent the prostate, in five the prostate and the seminal vesicles, and three gave an invalid answer. As far as the head-andneck case is concerned, four centers considered the macroscopic tumor only, one the tumor plus one lymph node (on the basis of their own CT interpretation), and six gave an invalid answer.

\section{Difficulties in GTV Evaluation}

Regarding the prostate case, eight of the eleven physicians stated that they had no difficulty in identifying the GTV on the CT, whereas for the head-and-neck case, only five of eleven had no difficulty.

\section{Definition of CTV, Organ Exclusion}

For the prostate case, six physicians considered the CTV to be equal to the GTV (i.e., the prostate or in some cases the prostate plus the seminal vesicles), four 
stated it was the GTV plus a margin, and one answer was invalid. The mean stated value of the margin between GTV and CTV was $4.1 \mathrm{~mm}$ (minimum 0, maximum $10 \mathrm{~mm}$; Figure 2a).

For the head-and-neck case, the CTV was defined as the GTV plus a margin in five, and CTV plus a margin plus the lymph nodes in four centers, and two responses were invalid. The median stated margin between GTV and CTV was $10.2 \mathrm{~mm}$ (Figure 2b). In eight head-and-neck situations, one or more organs were said to be excluded from CTV (five spinal cords, two bony structures, two parotids, one larynx, and one oropharynx). Three physicians did not state if they would exclude normal structures from CTV.

\section{Head-and-Neck Lymph Nodes}

Here, ten of twelve physicians gave fairly consistent responses (Table 1). Only one physician considered not to treat bilateral lymph nodes, and two considered not to include the supraclavicular and the inferior jugular areas.

\section{PTV Margins}

For the prostate case, physicians were asked to give a margin in three dimensions. The median stated values of margins between CTV and PTV were $9.4 \mathrm{~mm}$ (minimum 5, maximum $14 \mathrm{~mm}$ ), $11.0 \mathrm{~mm}$ (minimum 5, maximum $14 \mathrm{~mm}$ ), and $9.1 \mathrm{~mm}$ (minimum 5, maximum $14 \mathrm{~mm}$ ) in the anteroposterior (AP), craniocaudal (CC) and lateral (LAT) directions, respectively, with fairly wide differences between investigators (Figure 3a).

As far as the head-and-neck case is concerned, only one margin value was asked for. The median stated value between CTV and PTV was $7.0 \mathrm{~mm}$ (minimum 5, maximum 10; Figure 3b).

\section{Intraobserver Coherence}

For each institution, we measured the margins (GTV-CTV and CTV-PTV) drawn on the planning CT and compared them to the margins stated by the physician of that same institution. There was a good coherence for the prostate case except for one investigator (margin contoured: $5 \mathrm{~mm}$, margin stated: $10 \mathrm{~mm}$; Figure 4a).

With regard to the head-and-neck case, the intraobserver coherence was, on average, worse than that for the prostate case, most physicians drawing wider margins than those they had stated (Figure $4 b)$.

\section{Responses to the Questionnaire not Specifically Related to the Two Cases (Eleven Centers) CT for Planning}

When using CT for planning in prostate cancer, only three of eleven centers use contrast material. The median interval between CT slices is $5.8( \pm 2.4) \mathrm{mm}$ (range 3-10 $\mathrm{mm}$ ).
For head-and-neck cancer planning, also three of eleven centers use contrast for dedicated CT, and the median interval between slices is $5.9( \pm 2.1) \mathrm{mm}$ (range $3-10 \mathrm{~mm})$.

\section{Establishment of GTV}

When planning for prostate cancer, four centers routinely use other diagnostic tools (MRI, ultrasound) to define the GTV, and four ask for the help of a colleague from another specialty (i.e., radiologist).

For head-and-neck cancer planning, the large majority of physicians (ten of eleven) use other means (MRI, positron emission tomography [PET], endoscopic examination) and six out of eleven would associate a colleague from another specialty (i.e., head-and-neck surgeon, radiologist) to draw the GTV.

\section{Immobilization Devices}

In routine prostate cancer radiotherapy, six centers use an immobilization device including a rectal balloon in one. For ex-

Table 1. Results of the questionnaire on lymph nodes at risk in the T3 No Mo base-of-tongue cancer. Participants were asked to define the lymph node(s) group(s) they consider to be at risk of microscopic involvement (ten answers).

Tabelle 1. Ergebnisse des Fragebogens bezüglich Risiko-Lymphknotenstationen beim T3 No Mo-Zungengrundkarzinom. Die Teilnehmer wurden aufgefordert, die ihrer Meinung nach mit einem Risiko mikroskopischer Ausdehnung behafteten Lymphknotenstationen zu bestimmen (zehn Antworten).

\begin{tabular}{llcl}
\hline Lymph node areas & Yes, homolateral & Yes, bilateral & No \\
\hline Supraclavicular & 0 & 8 & 2 \\
Inferior jugular & 0 & 7 & 2 \\
Midjugular & 1 & 9 & 0 \\
Subdigastric & 0 & 10 & 0 \\
Superior jugular & 0 & 10 & 0 \\
Spinal & 0 & 9 & 1 \\
Submaxillary & 0 & 9 & 1 \\
\hline
\end{tabular}
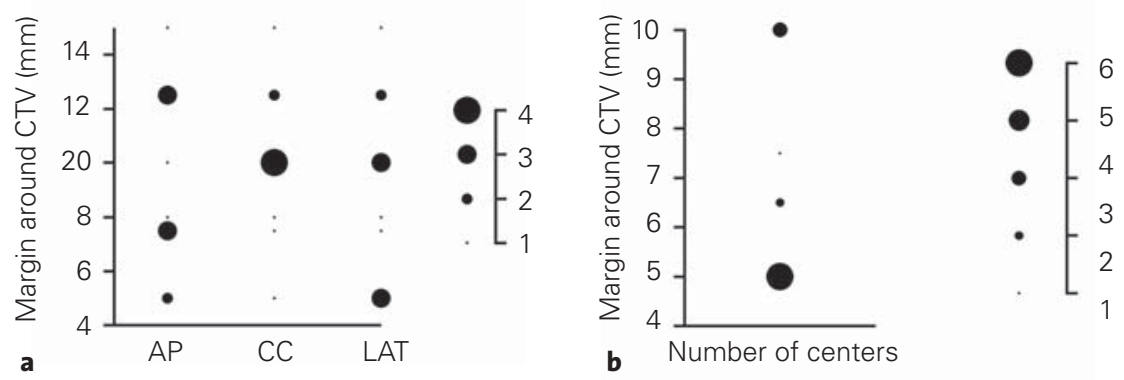

Figures $\mathbf{3 a}$ and $\mathbf{3} \mathbf{b}$. Distribution of reported margins to be applied on CTV for defining the PTV for the prostate (a) and the head-and-neck case (b).

Abbildungen $3 \mathbf{a}$ und $\mathbf{3} \mathbf{b}$. Verteilung der um das CTV gezeichneten Sicherheitssäume bei der Bestimmung des PTV beim Prostata- (a) und HNO-Karzinom (b). 

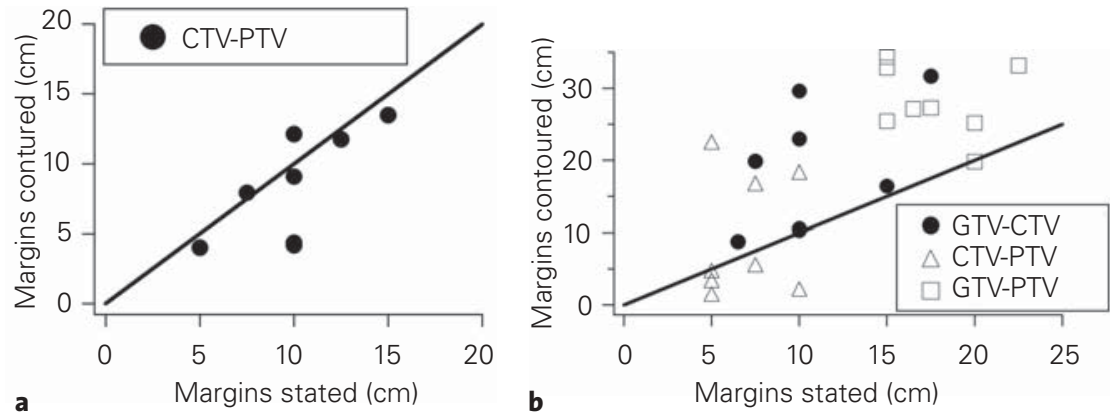

Figures $\mathbf{4 a}$ and $\mathbf{4} \mathbf{b}$. Correlation (coherence) between reported and practically implemented margin values in the target volume definition procedure for the prostate (a) and the headand-neck case (b).

Abbildungen $\mathbf{4 a}$ und $\mathbf{4 b}$. Korrelation (Übereinstimmung) zwischen berichteten und verwendeten Sicherheitssäumen in der Bestimmung der Zielvolumina beim Prostata- (a) und HNOKarzinom (b).

ternal immobilization, a thermoplastic cast and a device to support the legs is reported to be used.

All centers that participated routinely use an immobilization device (mask) for the treatment of head-and-neck cancer patients.

\section{Answers to the Poststudy Questionnaire}

The poststudy questionnaire was answered by only four physicians. After having reviewed their own delineation and compared it to those of other centers, two physicians would modify their CTV for the prostate case, and all four would change their head-and-neck volumes. Regarding the reasons for these large intercenter discrepancies in volume delineation, the following explanations were given: (1) insufficient quality of the images provided for the study, (2) lack of knowledge of ICRU definitions, and (3) variable clinical experience amongst physicians.

\section{Discussion}

Large variations in volume definition related to intra- and interobserver variability in contouring tumor targets are a well-known fact. These variations have been shown in many cancer sites, such as lung, prostate, brain, head-and-neck, esophagus and cervix [7, 13, 14, 19, 22, 24, 26-29, 32]. The magnitude of the discrepancies may vary from site to site, but for some locations, they may represent a major cause of error in radiotherapy planning and, consequently, a principal cause of treatment failure.

Although a number of hypotheses were made regarding the possible reasons for those physician-to-physician variations, as reviewed by Weiss \& Hess [31], only a few studies have been carried out in an attempt to identify the reasons for these discrepancies $[19,20]$. In this study, in which we confirm wide interobserver variations in a prostate and a head-andneck case [18], we aimed to identify at least some of the reasons of these variations: (a) by using an apparently simple case
(T1c N1 M0 carcinoma of the prostate) and a more difficult case (cT3 N0 M0 carcinoma of the base of tongue) and compare their relative interobserver variations, (b) by sending an ad hoc questionnaire with a series of questions related to each step (GTV, CTV, PTV) of the volume definition, and by comparing the answers given by each investigators, and, finally, (c) by correlating the answers given by individual physicians to their own displayed volumes.

\section{Comparison between the Prostate and the Head-and-Neck Case}

Although we had expected large interobserver variations in the base-oftongue cancer case, we were surprised to see also significant differences in all volumes in the apparently easy prostate example. Previous reports have suggested wider discrepancies in volumes in head-and-neck cancers [15, 27] than in prostate cancer $[6,7]$.

However, our hypothesis that a rather simple oncologic and radiologic situation will lead to less interobserver variation than a more complex one could not be readily confirmed in this study.

\section{GTV Definition}

Responses concerning GTV definition were inconsistent in both cases. Even with a relatively small number of physicians (eleven), it is striking to see how differently the ICRU recommendations have been interpreted for these two examples. In spite of this, eight of eleven physicians felt comfortable in identifying the prostate GTV, whereas less than half had no difficulty with the head-and-neck case. This is also reflected by the fact that six of eleven physicians would routinely associate a colleague from another specialty (radiologist, surgeon) while delineating head-and-neck target volume on CT.

Valicenti et al. [26] showed that there was an excellent agreement amongst observers in defining the prostate target volume, but poor agreement in that of the seminal vesicles. This, and the fact that in our case physicians were of different opinion with regard to GTV definition, could explain the unexpected wide GTV differences found in the prostate case.

Imaging data are of crucial importance for the definition of GTV. The use of contrast material for CT planning increases detectability and helps to define the borders of the malignancy or of an organ like the prostate $[26,31]$. In spite of this, only three physicians involved in our study state that they use it routinely in either situation. The variability of CT slice intervals and different use of additional diagnostic tools also reflect large differences in local planning habits.

The use of MRI in addition to CT has been shown to improve the accuracy of GTV both in prostate and head-and-neck 
cancer planning $[16,19]$ to decrease interobserver variation $[26,30]$, and, finally, to reduce the GTV [19-21]. The addition of PET and choline and acetate PET in case of prostate cancer may also offer further advantages in terms of tumor delineation [9].

\section{CTV Definition}

As for GTV, CTV definitions were inconsistent in both cases. In the ICRU 50 Report, it is stated that the CTV can include regional lymph nodes. Later in the questionnaire, all (eleven) investigators answered they would electively treat draining nodes, although only four physicians previously considered these part of the CTV. There was no agreement between investigators regarding CTV definition either in the prostate or in the base-of-tongue case. With regard to the margins between the GTV and CTV, the values reported were, on average, smaller $(4.1 \mathrm{~mm})$ for the prostate than for the head-and-neck case $(10.2 \mathrm{~mm})$, with less variation for the latter.

Thus, microscopic extent beyond the GTV was presumed to be smaller in case of prostate cancer than in case of base-of-tongue cancer. In a study by The et al. [25], extracapsular extension was found in $42 \%$ of 712 patients undergoing prostatectomy, and the median radial extension was $2 \mathrm{~mm}$ (range $0.5-12 \mathrm{~mm}$ ).

It is well recognized that oral and base-of-tongue cancers can be very infiltrative. Using the criteria by Anneroth et al. [1], Spiro et al. [23], in 137 surgical specimens of oral tongue cancers, demonstrated that 44 had a grade 3 pattern (margins containing small groups of cords of infiltrating cells) and 47 had grade 4 (marked cellular dissociation in small groups or even single cells). Base-of-tongue cancers are generally less differentiated, even more infiltrative and more advanced than oral tongue cancers [3]. Thus, a wider surgical or radiotherapy margin is deemed necessary.

The estimate of GTV-CTV margins can be hampered by a number of uncertainties, because microscopic extent can be extremely variable: depending on tumor type and site, microscopic disease can mean nodal, perineural, perivascular, intramuscular, intraparenchymal, perilymphatic, or bony extent. Imaging techniques are currently incapable of directly detecting areas of subclinical tumor involvement [4]. Therefore, the estimate of microscopic extent depends much on previous experience, based on pathologic studies of surgical specimens, or on patterns of failure after surgery or radiotherapy. This also accounts for the great variability in GTV-CTV margins between physicians. In our study, this is reflected by the fact that there was no agreement concerning the organs that should be excluded from the CTV (= "nontarget organs"). Subclinical nodal involvement was not considered in this early prostatic case, but certainly in the case of the T3 N0 M0 base-of-tongue cancer: for such a case, the lymph node CTV would include the anterior cervical chain, the spinal accessory nodes, the jugular nodes, the posterior submandibular nodes, and the supraclavicular nodes [15]. For the latter there was, surprisingly, a relatively good agreement regarding the lymph nodes deemed to be at risk of microscopic disease (see Table 1). This was perhaps facilitated by the fact that the case was that of a fairly large tumor with extension onto the midline, an indication for bilateral neck node irradiation [8]. The decision regarding the various levels of lymph nodes to be treated in the various head-and-neck cancers is a very complex one. In this respect, the groups at UCL, Brussels, Belgium [8], and Rotterdam, The Netherlands [33], have published excellent and comprehensive guidelines for the selection and delineation of lymph node target volumes in head-and-neck conformal radiotherapy. So, according to Grégoire et al., for a case of T3 N0 M0 base-of-tongue cancer, the CTV (with regard to the nodes) should include the lymphatics of levels IB, II, III, and IV on both sides of the neck, whereas level $\mathrm{V}$ should be included only if levels II and III are involved [8].

\section{PTV Margins}

In the prostate example, the stated margins between CTV and PTV in three dimensions varied considerably (Figure 3a). If related to literature data, the median stated values of $9.4 \mathrm{~mm}$ for AP, $11 \mathrm{~mm}$ for $\mathrm{CC}$ and $9 \mathrm{~mm}$ for LAT margins appear to be safe. Antolak et al. [2] have reported their measurement of the mobility of prostate CTV in three directions and summarized their data and those available from other groups. The translation in AP axis varied from 0.15 to $0.52 \mathrm{~cm}$, in CC from 0.17 to $0.50 \mathrm{~cm}$, and in LAT from 0.08 to $0.27 \mathrm{~cm}$.

It should be noted that the PTV accounts not only for physiological movements of tissues containing or surrounding the CTV, but also of patient's motion during treatment, and of day-to-day variation in patient setup, so the larger margins found in our exercise appear altogether reasonable.

In the head-and-neck case, the stated CTV-PTV margins were also quite variable (see Figure $3 b$ ). Five centers state they would add a $5-\mathrm{mm}$ margin and three centers a $10-\mathrm{mm}$ margin.

Contrary to prostate cancer, there have been very few studies on tissue mobility in case of base-of-tongue cancer, relevant to radiotherapy. In a group of 60 male and female normal controls, the mean hyoid displacement when swallowing $1 \mathrm{~cm}^{3}$ of liquid was $1.69 \mathrm{~cm}$ [12]. In a series of 20 patients who had received radiotherapy, mobility was decreased [12], but unfortunately, no data were obtained on patients with base-of-tongue cancer prior to treatment, to evaluate whether the presence of tumor per se would decrease mobility.

In our study, however, a 5-mm margin for PTV would appear tight in the case of the base-of-tongue cancer.

\section{Intraobserver Coherence}

Contrary to the other data of our study, there was a clear difference between the coherence results of the prostate and of the head-and-neck case (see Figures $4 a$ and $4 b$ ). In general, for 
the prostate exercise, physicians drew margins similar to those which they had stated, whereas for the head-and-neck situation, they tended to draw larger GTV-CTV and CTV-PTV margins than the values they have stated.

\section{Conclusion}

In this study, we confirmed that wide interobserver variations exist in the delineation of GTV, CTV and PTV, in two different oncologic cases.

Data to explain these discrepancies are scarce in the literature and suggest multifactorial and complex reasons. We suggest that part of these are due to:

(1) a variable knowledge and/or interpretation in the basic ICRU definitions;

(2) difficulties in the identification of GTV due to the available imaging quality;

(3) a variable understanding and/or concept for microscopic tumor extent (CTV);

(4) a variable knowledge and/or concept in the estimation of variations in position and movement of the CTV (GTV);

(5) a variable coherence between the theoretical knowledge (stated margins) and the practice (drawn margins).

Conceivably, measures can be taken to decrease discrepancies and, hopefully, improve interobserver coherence. To start with, a better and more comprehensive diffusion and understanding of ICRU recommendations in the radiation oncology community should be promoted. In parallel, continuous research in cancer imaging, in the knowledge of microscopic tumor extent and in a more systematic and individualized estimation of physiological motion should be supported.

\section{Acknowledgments}

The authors greatly appreciate the participation of physicians and physicists from radiooncology centers of the following hospitals or clinics: University Hospital, Basel; Oncology Institute of Southern Switzerland, Bellinzona; University Hospital, Bern; Cantonal Hospital, Chur; University Hospital, Geneva; Clinique de Genolier, Genolier; University Hospital, Lausanne; Cantonal Hospital, Lucerne; Cantonal Hospital, St. Gallen; Sion Hospital; University Hospital, Zurich.

The authors would like to thank Frances Godson for her editorial assistance.

\section{References}

1. Anneroth G, Batsakis J, Luna M. Review of the literature and a recommended system of malignancy grading in oral squamous carcinomas. Scand J Dent Res 1987;95:229-49.

2. Antolak JH, Rosen II, Childress $\mathrm{CH}$, et al. Prostate target volume variations during a course of radiotherapy. Int J Radiat Oncol Biol Phys 1998; 42:661-72.

3. Ashley DJB. Carcinoma of the cheek and floor of mouth. In: Ashley DJB, ed. Evans' histological appearance of tumours, 4th edn. Edinburgh: Churchill Livingstone, 1990:585-8.

4. Austin-Seymour M, Chen GT, Rosenman J, et al. Tumor and target delineation: current research and future challenges. Int J Radiat Oncol Biol Phys 1995;33:1041-52.
5. Cavey ML, Bayouth JE, Colman M, et al. IMRT to escalate the dose to the prostate while treating the pelvic nodes. Strahlenther Onkol 2005; 181:431-41.

6. Dubois DF, Prestidge BR, Hotchkiss LA, et al. Intra-observer and interobserver variability of MR imaging- and CT-derived prostate volumes after transperineal interstitial permanent prostate brachytherapy. Radiology 1998;207:785-9.

7. Fiorino C, Reni M, Bolognesi A, et al. Intra- and inter-observer variability in contouring prostate and seminal vesicles: implications for conformal treatment planning. Radiother Oncol 1998;47:285-92.

8. Grégoire V, Coche E, Cosnard G, et al. Selection and delineation of lymph node target volumes in head and neck conformal radiotherapy. Proposal for standardizing terminology and procedure based on surgical experience. Radiother Oncol 2000;56:135-50.

9. Grosu AL, Piert M, Weber WA, et al. Positron emission tomography for radiation treatment planning. Strahlenther Onkol 2005;181:483-99.

10. International Commission on Radiation Units and Measurements. Prescribing, recording and reporting photon beam therapy. ICRU Report 50. Bethesda: ICRU, 1993.

11. International Commission on Radiation Units and Measurements. Prescribing, recording and reporting photon beam therapy (supplement to ICRU Report 50). Report 62. Bethesda: ICRU, 1999.

12. Kendall KA, McKenzie SW, Leonard RJ, et al. Structural mobility in deglutition after single modality treatment of head and neck carcinomas with radiotherapy. Head Neck 1998;20:720-5.

13. Leunens G, Menten J, Weltens C, et al. Quality assessment of medical decision making in radiation oncology: variability in target volume delineation for brain tumours. Radiother Oncol 1993;29:169-75.

14. Logue JP, Sharrock CL, Cowan RA, et al. Clinical variability of target volume description in conformal radiotherapy planning. Int $\mathrm{J}$ Radiat Oncol Biol Phys 1999;41:929-31.

15. Million RR, Cassisi NJ, Mancuso AA. Oropharynx. In: Million RR, Cassisi NJ, eds. Management of head and neck cancer: a multidisciplinary approach, 2nd edn. Philadelphia: Lippincott, 1994;401-29.

16. Milosevic M, Voruganti S, Blend R, et al. Magnetic resonance imaging (MRI) for localisation of the prostate apex: comparison to computed tomography (CT) and urethrography. Radiother Oncol 1998;47:277-84.

17. Mock U, Bogner J, Georg D, et al. Comparative treatment planning on localized prostate carcinoma. Conformal photon- versus proton-based radiotherapy. Strahlenther Onkol 2005;181:448-55.

18. Moeckli R, Jeanneret-Sozzi W, Mirimanoff R-0, et al. The reasons for discrepancies in the target volume delineation: a SASRO study: physics aspects. 2005:submitted.

19. Rasch C, Keus R, Pameijer FA, et al. The potential impact of CT-MRI matching on tumor volume delineation in advanced head and neck cancer. Int J Radiat Oncol Biol Phys 1997;39:841-8.

20. Rasch C, Remeijer P, Koper PCM, et al. Comparison of prostate cancer treatment in two institutions: a quality control study. Int J Radiat Oncol Biol Phys 1999; 45:1055-62.

21. Sannazzari GL, Ragona R, Ruo Redda MG, et al. CT-MRI image fusion for delineation of volumes in three-dimensional conformal radiation therapy in the treatment of localised prostate cancer. Br J Radiol 2002;75:603-7.

22. Senan S, Van Sörnsen de Koste J, Samson M, et al. Evaluation of a target contouring protocol for 3D conformal radiotherapy in non-small cell lung cancer. Radiother Oncol 1999;53:247-55.

23. Spiro RH, Guillamondegni 0, Paulino AF, et al. Patterns of invasion and margin assessment in patients with oral tongue cancer. Head Neck 1999; 21:408-13.

24. Tai P, Van Dijk J, Yu E, et al. Variability of target volume delineation in cervical oesophageal cancer. Int J Radiat Oncol Biol Phys 1998;42:277-88.

25. The BS, Bastasch MD, Wheeler TM, et al. IMRT for prostate cancer: defining target volume based on correlated pathologic volume of disease. Int J Radiat Oncol Biol Phys 2003;56:184-91.

26. Valicenti RK, Sweet JW, Hauck WW, et al. Variation of clinical target volume definition in three dimensional conformal radiotherapy for prostate cancer. Int J Radiat Oncol Biol Phys 1999;44:931-5.

27. Valley JF, Bernier J, Tercier PA, et al. Quality assurance of the EORTC radiotherapy trial 22931 for head and neck carcinomas: the dummy run. Radiother Oncol 1998;47:37-44. 
28. Valley JF, Mirimanoff R0. Comparison of treatment techniques for lung cancer. Radiother Oncol 1993;28:168-73.

29. Van de Steene J, Linthout N, De Mey J, et al. Definition of gross tumor volume in lung cancer: inter-observer variability. Radiother Oncol 2002; 62:37-49.

30. Villeirs GM, Van Vaerenbergh K, Vakaet L, et al. Interobserver delineation variation using CT versus combined CT + MRI in intensity-modulated radiotherapy for prostate cancer. Strahlenther Onkol 2005;181: 424-30.

31. Weiss E, Hess CF. The impact of gross tumor volume (GTV) and clinical target volume (CTV) definition on the total accuracy in radiotherapy. Strahlenther Onkol 2003;179:21-30.

32. Weiss $E$, Richter $\mathrm{S}$, Krauss $\mathrm{T}$, et al. Conformal radiotherapy planning of cervix carcinoma: differences in the delineation of the clinical target volume. A comparison between gynaecologic and radiation oncologists. Radiother Oncol 2003;67:87-95.
33. Wijers $0 B$, Levendag PC, Tan $T$, et al. A simplified CT-based definition of the lymph node levels in the node-negative neck. Radiother Oncol 1999; 32:35-42.

Address for Correspondence

René-Olivier Mirimanoff, MD

Department of Radiation Oncology

University Hospital (CHUV)

Rue du Bugnon 21

1011 Lausanne

Switzerland

Phone (41.21) 314-4666, Fax -4664

e-mail: rene-olivier.mirimanoff@chuv.ch 